\title{
PENGETAHUAN REMAJA PUTRI TENTANG KOMPRES HANGAT MENGURANGI NYERI DISMENORE
}

\author{
Ridawati Sulaeman ${ }^{1}$, Risma yanti ${ }^{2}$ \\ ${ }^{1,2}$ Prodi DIII Keperawatan / Jurusan Keperawatan /Poltekkes Kemenkes Mataram / Indonesia
}

\begin{abstract}
Abstrak
Latar Belakang : Dismenore adalah rasa nyeri pada perut bagian bawah selama menstruasi. Rasa nyeri dapat disertai perasaan kram, mual, muntah, diare dan pusing. Dismenorea merupakan masalah umum dan dapat mempunyai dampak produktivitas wanita menurun, $50 \%$ Wanita yang menstruasi mengalami dismenorea dan sekitar $10 \%$ nya mengalami gejala yang hebat sehingga tidak dapat melakukan aktifitas atau harus beristirahat di tempat tidur (Hacker \& Moore, 2001). Penelitian yang dilakukan Kurniawati \& Kusumawati (2011) di SMK Batik I Surakarta menunjukkan bahwa $34 \%$ siswa yang mengalami dismenorea tidak mengikuti kegiatan sekolah, $34 \%$ hanya tiduran dan $34 \%$ sulit belajar. Hasil studi pendahuluan di MTs Nurul Islam Dasan Baru, terhadap 10 siswi kelas VII, VIII dan IX dari 10 orang siswi yang diwawancara, 9 diantaranya mengaku mengalami nyeri ketika haid, 8 diantaranya mengalami nyeri ringan sampai dengan sedang, sedangkan 1 orang lainnya mengalami nyeri berat. Tujuan penelitian ini untuk mengukur pengetahuan remaja putri tentang tindakan kompres hangat mengurangi nyeri dismenore.

Metode Penelitian : Desain penelitian deskriptif. Populasi 50 siswi di MTs Nurul Islam Dasan Baru. Cara pengambilan sampel menggunakan total sampling. Instrumen yang digunakan yaitu kuesioner.

Hasil: penelitian menunjukkan pengetahuan remaja putri tentang kompres hangat mengurangi dismenorea kurang 33 orang (66\%), cukup 12 orang (24\%) dan kurang 5 orang (10\%).

Kesimpulan :penelitian ini menunjukkan yaitu sebagian besar responden berpengatahuan kurang. Bagi responden agar dapat meningkatkan pengetahuan tentang dismenore dan cara penanganannya melalui berbagai sumber informasi.
\end{abstract}

Kata Kunci: Pengetahuan, Remaja Putri, Nyeri, Dismenore, Kompres Hangat

\section{TEENAGE GIRL'S KNOWLEDGE ABOUT WARM COMPRESSES IN REDUCING PAIN} OF DYSMENORRHEA

\begin{abstract}
Background : Dysmenorrhea is pain in the lower abdomen during menstruation. The pain can be accompanied by feelings of cramps, nausea, vomiting, diarrhea and dizziness. Dysmenorrhoea is a common problem and can have a decreased impact on women's productivity, $50 \%$ of menstruating women experience dysmenorrhoea and about $10 \%$ experience severe symptoms so they cannot perform activities or have to rest in bed (Hacker and Moore, 2010). Research conducted by Kurniawati and Kusumawati (2011) at SMK Batik I Surakarta shows that 34\% of students who experience dysmenorrhoea do not attend school activities, 34\% only lie down and 34\% find it difficult to learn. The results of a preliminary study at MTs Nurul Islam Dasan Baru, of 10 class VII, VIII and IX female students from 10 interviewed students, 9 of whom claimed to experience pain during menstruation, 8 of whom experienced mild to moderate pain, while 1 other person experienced severe pain . The purpose of this study was to determine the knowledge of young women about the action of warm compresses to reduce dysmenorrhea pain. Research methods: Descriptive research design. Population of 50 female students at MTs Nurul Islam Dasan Baru. How to take samples using total
\end{abstract}


sampling. The instrument used was a questionnaire. Results shows the knowledge of teenage girl about warm compresses reducing dysmenorrhoea by 33 people (66\%), 12 people (24\%) and 5 people (10\%). Conclusion: this research shows that most of the respondents are knowledgeable. For respondents to be able to increase knowledge about dysmenorrhea and how to handle it through various sources of information.

Keywords: Knowledge, Teenage girl, Pain, Dysmenorrhea, Warm Compress

\section{PENDAHULUAN}

Dismenore adalah rasa nyeri pada perut bagian bawah selama menstruasi. Rasa nyeri dapat disertai perasaan kram, mual, muntah, diare dan pusing. Dismenorea merupakan masalah umum dan dapat mempunyai dampak produktivitas wanita menurun, $50 \%$ Wanita yang menstruasi mengalami dismenorea dan sekitar $10 \%$ nya mengalami gejala yang hebat sehingga tidak dapat melakukan aktifitas atau harus beristirahat di tempat tidur (Hacker \& Moore, 2001). Penelitian yang dilakukan Kurniawati dan Kusumawati (2011) di SMK Batik I Surakarta menunjukkan bahwa $34 \%$ siswa yang mengalami dismenorea tidak mengikuti kegiatan sekolah, $34 \%$ hanya tiduran dan $34 \%$ sulit belajar.

Dismenore terjadi akibat peningkatan produksi prostaglandin dan pelepasannya (terutama $\mathrm{PGF}_{2 \alpha}$ ) dari endometrium selama menstruasi menyebabkan kontraksi uterus yang tidak terkoordinasi dan tidak teratur sehingga timbul nyeri. Selama periode menstruasi, wanita yang mengalami dismenore mempunyai tekanan intrauteri yang lebih tinggi dan memiliki kadar prostaglandin dua kali lebih banyak dalam darah menstruasi dibandingkan wanita yang tidak mengalami nyeri. Kontraksi uterus lebih sering terjadi dan tidak terkoordinasi atau tidak teratur. Akibat peningkatan aktivitas uterus yang abnormal ini, aliran darah menjadi berkurang sehingga terjadi iskemia atau hipoksia uterus yang menyebabkan nyeri. Mekanisme nyeri lainnya disebabkan oleh prostaglandin $\left(\mathrm{PGE}_{2}\right)$ dan hormon lain yang membuat saraf-saraf sensori nyeri di uterus menjadi hipersensitif terhadap kerja bradikinin serta stimulus nyeri fisik dan kimiawi lainnya. Kadar vasopresin sirkulasi mengalami peningkatan selama menstruasi pada wanita yang mengalami dismenore primer. Apabila disertai peningkatan kadar oksitosin, kadar vasopresin yang lebih tinggi menyebabkan ketidakteraturan kontraksi uterus yang menyebabkan hipoksia dan iskemia uterus. Pada wanita yang mengalami dismenore primer tanpa disertai peningkatan prostaglandin akan terjadi peningkatan aktivitas alur 5lopoksigenase. Kondisi ini menyebabkan peningkatan sintesis leukotrien, vasokonstriktor sangat kuat yang menginduksi kontraksi otot uterus (Kusmiran, 2012)

Ada beberapa cara untuk mengurangi rasa nyeri akibat dismenore yaitu salah satunya kompres hangat. Kompres hangat merupakan salah satu tindakan mandiri. Kompres hangat adalah memberikan rasa hangat untuk memenuhi kebutuhan rasa nyaman, mengurangi atau membebaskan nyeri, mengurangi atau mencegah spasme otot dan memberikan rasa hangat pada daerah tertentu (Uliyah \& Hidayat, 2009). Pengaruh kompres hangat yang memberikan efek hangat pada bagian tubuh yang dapat menyalurkan oksigen pada pembuluh darah yang ada di uterus sehingga tidak menghambat 
aliran darah. Pemberian kompres hangat pada daerah tubuh akan memberikan sinyal kehipotalamus melalui sum-sum tulang belakang. Ketika reseptor yang peka terhadap panas hipotalamus di rangsang, system efek mengeluarkan sinyal yang memulai berkeringat dan vasodilatasi perifer. Perubahan ukuran pembuluh darah di atur oleh pusat vasomotor pada medulla oblongata dari tangkai otak, di bawah pengaruh hipotalamik bagian anterior sehingga terjadi vasodilatasi pada pembuluh darah yang nantinya akan meningkatkan aliran darah kejaringan penyaluran zat asam dan makanan ke sel-sel di perbesar dan pembuangan dari zat-zat diperbaiki yang dapat mengurangi rasa nyeri haid primer yang di sebabkan suplai darah ke endometrium kurang (Indriyani, Sari, \& Sarinengsih, 2012).

Hasil studi pendahuluan di MTs Nurul Islam Dasan Baru (2018), terhadap 10 siswi kelas VII, VIII dan IX dari 10 orang siswi yang diwawancara, 9 diantaranya mengaku mengalami nyeri ketika haid, 8 diantaranya mengalami nyeri ringan sampai dengan sedang, sedangkan 1 orang lainnya mengalami nyeri berat. Berdasarkan hal tersebut, maka peneliti bertujuan mengukur pengetahuan remaja putri tentang tindakan kompres hangat mengurangi nyeri dismenore.

\section{METODE}

Desain penelitian ini menggunakan deskriptif, dimana penelitian ini mengeskplorasi pengetahuan remaja putri MTs Nurul Islam Dasan Baru tentang tindakan kompres hangat mengurangi nyeri dismenore (Nursalam, 2016). Populasi adalah seluruh rema ja putri kelas VII, VIII dan IX sebanyak 50 responden. Cara pengambilan sampel secara total sampling. Cara pengumpulan data menggunakan kuesioner. Pengolahan data menggunakan ketegori baik bila hasil prosentase 76\%$100 \%$, cukup prosentase $56 \%-75 \%$ dan kurang prosentase $<56 \%$.

\section{HASIL PENELITIAN}

\section{A. Karakteristik Respondensi}

Karakteristik responden meliputi umur, umur menarche dan keterpaparan sumber informasi. Untuk lebih jelasnya dapat dilihat pada tabel 1 :

\begin{tabular}{lccc}
\hline & Variabel & $\sum$ & $\%$ \\
\hline Umur & & & 38 \\
\hline 13 & 19 & 30 \\
\hline 14 & 15 & 22 \\
\hline 15 & 11 & 10 \\
\hline Umur Menarche & Total & 5 & 100 \\
\hline & 11 & 50 & 4 \\
\hline 12 & & 46 \\
\hline 13 & 2 & 42 \\
\hline 14 & 23 & 8 \\
\hline Total & 4 & 100 \\
\hline
\end{tabular}




\begin{tabular}{ccc}
\hline Keterpaparan Sumber Informasi & & \\
\hline Pernah & 18 & 36 \\
\hline Tidak pernah & 32 & 64 \\
\hline Total & 50 & 100 \\
\hline
\end{tabular}

Tabel 1 menunjukkan umur responden sebagian besar umur 13 tahun sebanyak 19 orang ( 38

$\%$ ), umur menarche sebagian besar 23 orang (46\%) dan tidak pernah terpapar sumber informasi sebanyak 32 orang $(64 \%)$.

B. Hasil Penelitian Pengetahuan Remaja Putri

Tabel 2 menunjukkan hasil penelitian tentang pengetahuan remaja putri tentang kompres hangat mengurangi nyeri dismenorea.

\begin{tabular}{cccc}
\hline No & Pengetahuan & Frekuensi & Persentase \\
\hline 1 & Baik & 5 & 10 \\
\hline 2 & Cukup & 12 & 24 \\
\hline 3 & Kurang & 33 & 66 \\
\hline & Total & 50 & 100
\end{tabular}

Tabel 2 menunjukkan bahwa responden sebagian besar berpengetahuan kurang yaitu sebanyak 33 responden (66\%).

\section{PEMBAHASAN}

Hasil penelitian menunjukan bahwa responden sebagian besar berpengetahuan kurang sebanayk $66 \%$, cukup sebanyak $24 \%$, dan kurang sebanyak $10 \%$. Hal ini disebabkan responden tidak memahami tentang penggunaan kompres hangat pada saat terjadi dismenorea, indikasi penggunaan kompres hangat, alat yang digunakan, lokasi tempat meletakkan kompres hangat, lama pemberian tindakan, suhu air hangat yang digunakan. Kurangnya pengetahuan siswi di karenakan dari pihak sekolah sendiri belum pernah memberikan penyuluhan atau informasi tentang dismenore, dari petugas UKS juga belum pernah memberikan informasi tentang dismenore dan belum pernah menerapkan cara penanganan menggunakan kompres hangat pada siswi yang mengalami dismenore dan juga dikarenakan kurangnya minat atau kepedulian siswi untuk mengakses informasi tentang nyeri dismenore dan cara penanganannya melalui sosial media seperti internet, majalah, koran dan referensi mengenai penanganan dismenore. Selain faktor kurangnya informasi, siswa juga mengatakan bahwa nyeri pada saat haid merupakan hal biasa dan menerima keadaan tersebut sebagai kodratnya seorang wanita, walaupun dapat mengganggu aktifitasnya untuk tidak mengikuti proses pembelajaran.

Penelitian ini sejalan dengan penelitian WIdyasari (2016) yang berjudul "Hubungan penggunaan media massa dengan tingkat pengetahuan remaja putri dalam penanganan dismenore di SMA Karya Ibu Palembang” hasil responden terbanyak dengan pengetahuan kurang yaitu 53,5\%. Penyebab kurangnya pengetahuan siswi di SMA Karya Ibu Palembang karena ketidakpedulian siswi untuk mengakses penanganan nyeri dismenore melalui media massa. 
Pengetahuan seseorang terhadap suatu objek mempunyai intensitas atau tingkat yang berbedabeda. Sumber informasi, usia, pendidikan, sosial, ekonomi dan budaya dapat mempengaruhi tingkat pengetahuan seseorang (Febryary, Astuti, \& Hartinah, 2016). Hal ini sejalan dengan teori yang dikemukakan oleh Budiman \& Riyanto (2013) yang menyatakan bahwa Informasi mempengaruhi pengetahuan seseorang jika sering mendapatkan informasi tentang suatu pembelajaran maka akan menambah pengetahuan dan wawasannya, sedangkan seseorang yang tidak sering menerima informasi tidak akan menambah pengetahuan dan wawasannya.

Seseorang memiliki sumber informasi yang banyak akan memiki pengetahuan yang baik pula (Notoatmodjo, 2012). Salah satu sumber informasi yang berperan penting bagi pengetahuan yaitu media massa, Semakin banyak informasi yang seseorang peroleh maka pengetahuan akan semakin luas dan sebaliknya jika seseorang memiliki pengalaman dan wawasan yang sempit maka pengetahuan seseorang juga kurang (Notoatmodjo, 2012). Hal ini sesuai dengan teori Notoadmodjo (2012) bahwa pengetahuan adalah hasil pengindraan manusia, atau hasil tahu seseorang terhadap obyek melalui indra yang dimilikinya (mata, hidung, telinga dan sebagainya).

Informasi mengenai penanganan nyeri pada saat menstruasi sangat di perlukan untuk memberikan rasa nyaman kepada remaja putri yang mengalaminya. Nyeri yang berkelanjutan dapat menurunkan produktivitas seseorang sehingga dapat menyebabkan tertinggalnya kegiatan - kegiatan yang berarti dalam kehidupan sehari - hari misalnya : tertinggalnya pelajaran di sekolah, tertinggalnya sosialisasi dengan teman dan nyeri yang tidak tertanggulangi secara terus menerus tanpa penanganan yang serius (professional) dapat mengganggu sistem reproduksi (Merdianita, Anugraheni, \& Wahyuningsih, 2013)

Banyak cara untuk mengatasi rasa nyeri pada saat menstruasi yaitu secara farmakologi (obatobatan) dan non farmakologi (tanpa menggunakan obat-obatan). Salah satu cara non farmakologi adalah melakukan kompres hangat pada daerah yang mengalami nyeri ( perut dan pinggang). Menurut Potter \& Perry (2006), prinsip kerja kompres hangat dengan mempergunakan buli-buli panas yang dibungkus kain yaitu secara konduksi dimana terjadi pemindahan panas dari bulibuli ke dalam tubuh sehingga akan menyebabkan pelebaran pembuluh darah dan akan terjadi penurunan ketegangan otot sehingga nyeri haid yang dirasakan akan berkurang atau hilang. Selain melakukan kompres hangat juga didukung oleh kegiatan aktif bergerak, perhatikan asupan makanan, minum teh chamomile, minum wedang jahe, dan hindari stress (Anugro \& Wulandari, 2011).

\section{KESIMPULAN}

Berdasarkan penelitian yang telah dilaksanakan pada tanggal 29April 2019 di MTs Nurul Islam Dasan Baru mengenai Pengetahuan Remaja Putri Tentang Kompres Hangat untuk Mengurangi Nyeri Dismenore di MTs Nurul Islam Dasan Baru dapat ditarik kesimpulan, yaitu sebagian besar 
responden berpengetahuan kurang sebanyak 66\%. Kurangnya pengetahuan siswi di karenakan dari pihak sekolah belum maksimal memberikan penyuluhan atau informasi tentang dismenore, petugas UKS belum memberikan informasi tentang dismenore dan penerapan cara penanganan menggunakan kompres hangat pada siswi yang mengalami dismenore dan juga dikarenakan kurangnya minat atau kepedulian siswi untuk mengakses informasi tentang nyeri dismenore dan cara penanganannya melalui sosial media seperti internet sehingga disarankan untuk meningkatkan minat siswi untuk mengakses informasi mengenai dismenorea diharapkan membuat media informasi yang menarik untuk menangani dismenore.

\section{DAFTAR PUSTAKA}

Anugro, D., \& Wulandari, A. (2011). Cara Jitu Mengatasi Nyeri Haid. Yogyakarta: Andi Publisher.

Budiman, \& Riyanto. (2013). Informasi dan Pengetahuan Kesehatan. Jakarta: Rineka Cipta.

Febryary, D. R., Astuti, S., \& Hartinah, H. (2016). Gambaran Pengetahuan, Sikap Dan Perilaku Remaja Putri Dalam Penanganan Keputihan Di Desa Cilayung. Jurnal Sistem Kesehatan, 2(1), 40-46. https://doi.org/10.24198/jsk.v2i1.10418

Hacker, \& Moore. (2001). Esensial Obstetri dan Ginekologi. Jakarta: Hipokrates.

Indriyani, Y. D., Sari, Y. R., \& Sarinengsih, Y. (2012). Pengaruh Kompres Hangat Terhadap Nyeri Haid Pada Remaja Putri Di Dusun Kebonhui Dan Dusun Pangkalan Desa Margajaya Kecamatan Tanjungsari Kabupaten Sumedang. Bhakti Kencana Medika, 2(4).

Kurniawati, D., \& Kusumawati, Y. (2011). Pengaruh Dismenore Terhadap Aktivitas Pada Siswi Smk. KESMAS - Jurnal Kesehatan Masyarakat, 6(2), 93-99. https://doi.org/10.15294/kemas.v6i2.1758

Kusmiran, E. (2012). Kesehatan Reproduksi Remaja Dan Wanita (2nd ed.). Jakarta: Salemba Medika.

Merdianita, V., Anugraheni, D., \& Wahyuningsih, A. (2013). Efektifitas Kompres Hangat Dalam Menurunkan Intensitas Nyeri Dysmenorrhoea Pada Mahasiswi Stikes Rs. Baptis Kediri. Jurnal STIKES, 6(1), 1-10.

MTs Nurul Islam Dasan Baru. (2018). Profil MTs Nurul Islam Dasan Baru.

Notoatmodjo. (2012). Metodologi Penelitian Kesehatan. Jakarta: Rineka Cipta.

Nursalam. (2016). Metodologi Ilmu Keperawatan. Jakarta: Salemba Medika.

Potter, P. A., \& Perry, A. G. (2006). Fundamental Keperawatan. Jakarta: EGC.

Uliyah, M., \& Hidayat, A. (2009). Praktikum Klinik: Aplikasi Dasar-Dasar Praktik Kebidanan. Jakarta: Salemba Medika.

WIdyasari, D. (2016). Hubungan penggunaan media massa dengan tingkat pengetahuan remaja putri dalam penanganan dismenore di SMA Karya Ibu Palembang. Retrieved June 11, 2019, from http://eprints.undip.ac.id./3834/6/1/3999.pdf 